\title{
Experimental Cum Analytical Study On Effect Of Wall Materials In Thermal Comfort Index Of Institutional Building
}

DOI:10.36909/jer.ACMM.16309

\author{
Guru Kumar ${ }^{1}$, Balasubramanian ${ }^{2} *$, Krishnaraj ${ }^{3}$, Prasath $\mathrm{Kumar}^{4}$, Monisha Ravi $^{5}$ \\ 1,2,3,4,5 Department of civil engineering, SRM Institute of Science and Technology, India. \\ *Corresponding Author Email Id: balamv86@gmail.com.
}

\begin{abstract}
The importance of sustainability has become one of the major priorities in the field of construction with $40 \%$ of total energy worldwide while account for $25 \%$ of carbon dioxide emissions are due to buildings. Thus, the implementation of sustainability along with use of Building Information Modelling (BIM) tools are employed in this research to perform energy analysis on buildings using various sustainable materials. The results showed that the incorporation of sustainable materials with low thermal conductivity could reduce the indoor air temperature by $8{ }^{\circ} \mathrm{C}$ and the overall electricity consumption by $30 \%$ and carbon emission from $15 \%$ to $48 \%$ while lowering construction costs.
\end{abstract}

Keywords: BIM, Green materials, Indoor Air Temperature, Sustainability, Thermal Conductivity

\section{INTRODUCTION}

Construction industry is one of the biggest and most prominent industry worldwide. It helps in contributing around six to nine percentage to the overall gross domestic product of various developing nations. Technological advancements are growing day by day in the construction field with new techniques and equipment being invented in numerous numbers. From living in caves and huts to skyscrapers almost going beyond clouds, the construction industry has come a long way. Buildings are an integral part of everyone's life since it provides a secure and a peaceful environment to carry out their day-to-day activities. It also helps in providing the general facilities 
required and care has to be taken by the engineers that the building being constructed satisfies the necessary standards provided based on the region of the construction site. Although construction of buildings can pose widespread, direct as well as indirect effect on the society, economy as well as the environment. Buildings are one of the largest consumers of energy worldwide (Pezeshki, Soleimani, and Darabi 2019). They consume around $40 \%$ of energy globally and carbon dioxide emission of around 25\% (Metz et al. 2008). Most of the energy is said to be consumed during the operational phase of the building (Guo and Wei 2016). The reduction in energy consumption by using sustainable practices is also directly associated with the increase of costs, which augments the slower adaptation (Bueno and Fabricio 2018). Overall, the inadequacy of the construction contractors and the ignorance of the customers retards the incorporation of sustainability in the process of construction. However, numerous products are being promoted in the market, which are sustainable, and green materials, the consumers are skeptical in the incorporation of these products due to the lack of awareness and the various benefits of those products on comparison with the conventional materials (Monisha et al 2021). The application of sustainable materials in the process of building construction can not only help in reducing the overall carbon emission but also can curb the overall energy consumed by the building during its occupancy stage thus reducing the cost incurred for the operation of the building while safe-guarding the environment. This helps the future generations in providing a more clean and beautiful surroundings to live in. Previously, extensive research is carried out on identifying the thermal comfort of buildings with a specific material, building simulation analysis towards energy-efficient buildings. This research mainly focuses on providing an in-depth comparison of multiple locally available sustainable materials, which not only are structurally sound but could also prove to be energy-saving, cost-efficient, and have an impact on the thermal comfort of the buildings while reducing its energy consumption by appropriate analysis using BIM tools (Gurukumar et al. 2021) and (Dineshraju et al. 2020). This study covers building simulation analysis at different dimensions using various parameters such as indoor air temperature, conduction gains, retrofitting procedures, chillers energy consumption, total cost and electricity, and the sustainability of the whole building. There is minimal research on a different dimension of building simulation analysis at a single point, so the attempt made in this study to understand the overall effect of the sustainable materials compared with the conventional materials by comparing different parameters in building simulation. Hence, this study extends to investigate a real-time case of an educational building located in Chennai, India is chosen in warm 
and humid climatic conditions.

\section{RESEARCH METHODOLOGY}

The majority of any building envelope as represented by the Energy Conservation Building Code (ECBC) (India 2017) consists of the opaque external walls, vertical fenestration or glazing, roofing systems. These three systems are most responsible for the thermal comfort of the building governing the external factors. The external factors could be the solar radiation, climatic conditions, and wind flow. Table 1 represents the various types of materials as prescribed by ECBC as potential materials that could be used in the building envelope(India 2017).

Table 1: Building envelope materials listed in ECBC standards

\begin{tabular}{|c|c|c|c|}
\hline MATERIAL NAME & APPLICATION & DENSITY $\left(\mathrm{kg} / \mathrm{m}^{3}\right)$ & $\begin{array}{c}\text { THERMAL } \\
\text { CONDUCTIVITY } \\
(\mathrm{W} / \mathrm{mk})\end{array}$ \\
\hline $\begin{array}{c}\text { Autoclaved Aerated } \\
\text { Concrete block }\end{array}$ & Opaque External Wall & 642 & 0.18 \\
\hline Clay tile & Roofing System & 2531 & 0.6323 \\
\hline Concrete block & Opaque External Wall & 2427 & 1.39 \\
\hline Fired Bricks & Opaque External Wall & 2049 & 1.27 \\
\hline Tinted Glass & Vertical Fenestration & 2500 & 1.04 \\
\hline Clear Glass & Vertical Fenestration & 2477 & 1.05 \\
\hline Mangalore Roof Tile & Roofing System & 2531 & 0.60 \\
\hline
\end{tabular}

The type of materials used, its properties and performance in the walls of the building determine its ability to conduct the heat inside the building if the building is located in tropical regions or its ability to insulate the building from lower temperatures in colder regions. The vertical fenestration of the building determines the ventilation inside the building if it is non air conditioned and the amount of sunlight that is allowed inside the building based on the size and orientation of the windows. The roofing systems majorly affect the top occupied floor of the building since it being responsible for conduction of solar energy through the roof into the building throughout the day. Figure 1 represents the type of conduction gain each form of building envelope and the way it 
affects the building in terms of occupants as well as its construction and operational costs. The following section explains the various materials that could replace the conventional materials used along with its properties in the building envelope.

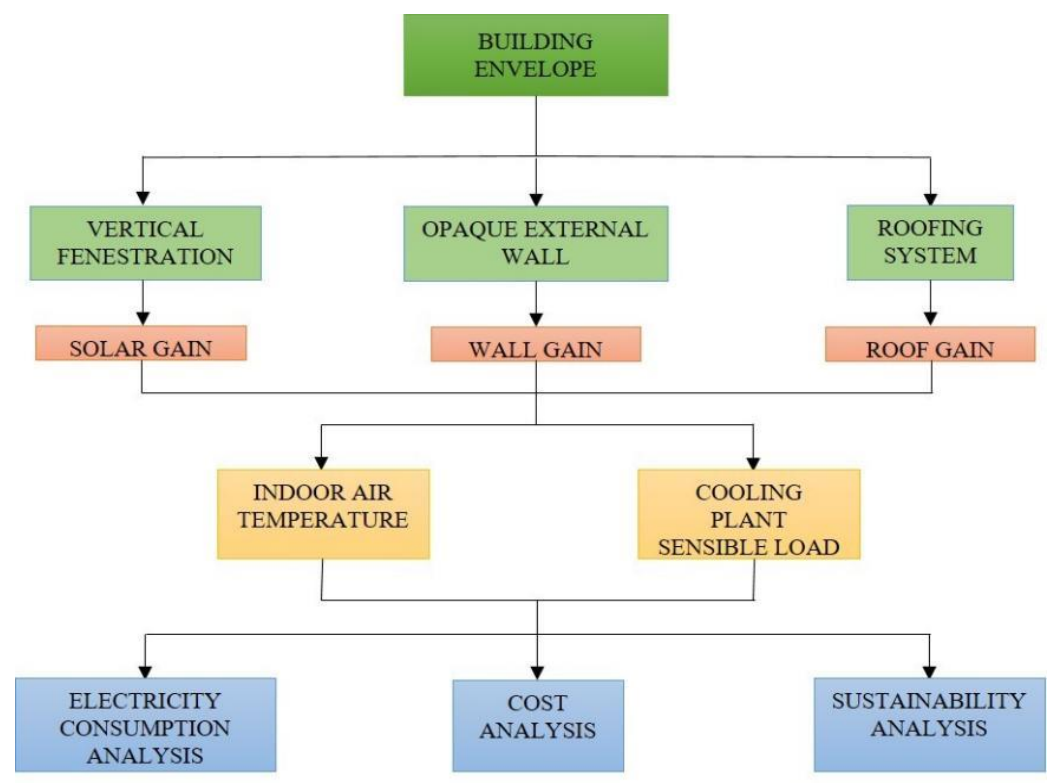

Figure 1: Represents the type of conduction gain each form of building

Table 2: Shows the Material properties

\begin{tabular}{|c|c|c|c|c|c|c|c|}
\hline $\begin{array}{c}\text { S. } \\
\text { No }\end{array}$ & $\begin{array}{l}\text { Name of } \\
\text { Material }\end{array}$ & $\begin{array}{l}\text { Density } \\
\left(\mathrm{kg} / \mathrm{m}^{3}\right)\end{array}$ & $\begin{array}{c}\text { Compressive } \\
\text { strength } \\
\left(\mathrm{N} / \mathbf{m m}^{2}\right)\end{array}$ & $\begin{array}{c}\text { Thermal } \\
\text { conductivity } \\
(\mathrm{W} / \mathrm{mk})\end{array}$ & $\begin{array}{c}\text { Embodied } \\
\text { energy } \\
\left(\mathbf{M J} / \mathbf{m}^{3}\right)\end{array}$ & $\begin{array}{c}\mathrm{CO}_{2} \\
\text { Emissions } \\
\left(\mathbf{k g} / \mathbf{m}^{3}\right)\end{array}$ & $\begin{array}{c}\text { Cost } \\
\text { (Rs/unit) }\end{array}$ \\
\hline 1 & $\begin{array}{l}\text { AAC } \\
\text { block }\end{array}$ & 550 & 3 & 0.13 & 819 & 80 & 68 \\
\hline 2 & CSEB & 1900 & $3-7$ & 0.46 & 572.58 & 49.37 & 25 \\
\hline 3 & $\begin{array}{l}\text { Fired } \\
\text { Bricks }\end{array}$ & 1700 & 3.5 & 0.84 & 2550 & 250 & 8 \\
\hline 4 & $\begin{array}{c}\text { Solid } \\
\text { concrete } \\
\text { blocks }\end{array}$ & 2240 & $3.5-5$ & 1.1 & 971 & 95 & 38 \\
\hline
\end{tabular}

\section{Solid Concrete blocks}

Solid concrete blocks are one of the widely used conventional materials, which can be used in load bearing walls as well as in buildings with framed structures. It is manufactured by mixing aggregate chips of $6 \mathrm{~mm}$, river or manufactured sand, water and cement in the required proportion in a way it reaches a minimum strength of $3.5 \mathrm{~N} / \mathrm{mm}^{2}$. It is then casted either manually or mechanically and allowed to cure for 28 days before it can be utilized for construction. The blocks have excellent 
strength and durability properties but possess relatively high thermal conductivity compared to the other materials. The properties of solid concrete blocks are tabulated in table 2.

\section{Measurement of thermal conductivity}

The thermal conductivity of the materials was determined using Hot Disk TPS 2500S Thermal Analyzer as shown in figure 2. It employs a transient plane source method which helps in determining the thermal conductivity and thermal diffusivity of the materials along with its specific heat (Warzoha and Fleischer 2014). It uses a transiently heated plane sensor, in this case a Kapton insulated sensor with a double spiral coil conducting electricity etched in a nickel foil (Ashraf 2016). The sensor can be used to measure the thermal conductivity of the material with both single side and double sided testing. The single sided testing was adopted for which the sensor is placed over the material and above which an insulating material, preferably thermocol provided along with the apparatus and a steel ring to hold the setting in place as shown in figure 3. A standard heating power of $100 \mathrm{~mW}$ was generated by the foil to measure the thermal conductivity for a period of 20 seconds for all the materials. The sensor generates the heat and at the same time measures the heat resistance as a function of time hence providing the thermal conductivity value (He 2005a; 2005b; Al-Ajlan 2006). The thermal conductivity values are then tabulated as shown in table 2 , which is used for further analysis.
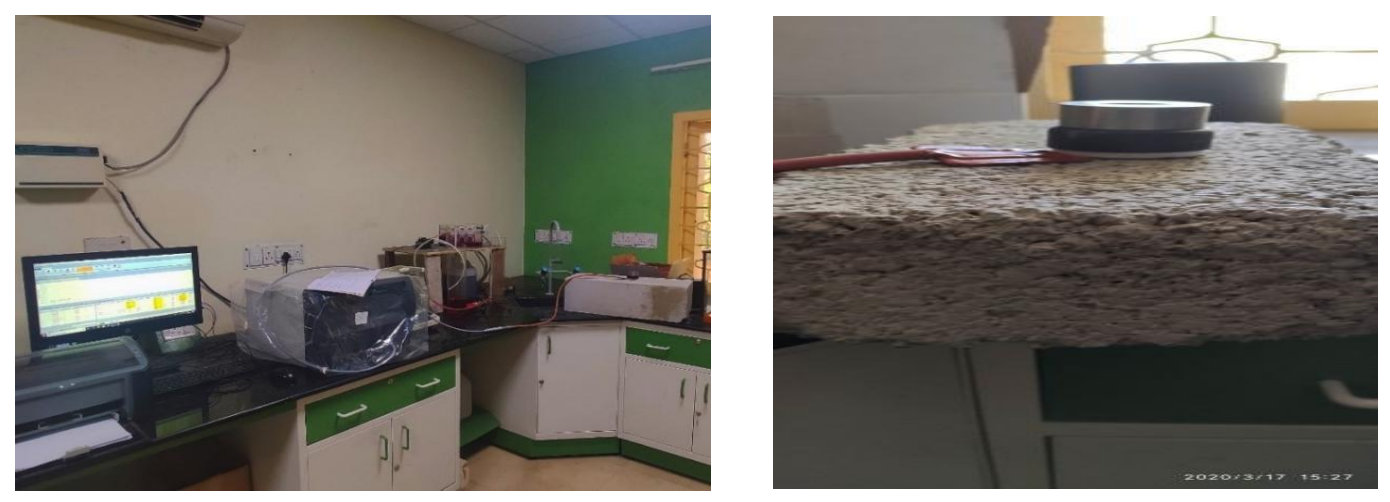

Figure 2 \& Figure 3: Shows the apparatus and a steel ring to hold the setting in place

\section{Simulation Model}

The building used for the simulation process is the classroom complex within a university complex located in Chennai, India. The various details about the building is provided in Table 3. 
Table 3: Represents the Project Details

\begin{tabular}{|l|l|}
\hline Number of storeys & $\mathrm{G}+7$ \\
\hline Type of construction & Framed structure \\
\hline Type of wall material & Concrete block \\
\hline Total built up area & $4039 \mathrm{~m}^{2}$ \\
\hline Number of occupied spaces & $\begin{array}{l}4 \text { Air conditioned rooms, 25 non air } \\
\text { conditioned rooms }\end{array}$ \\
\hline Climatic zone & Warm and Humid \\
\hline
\end{tabular}

The building was modeled using Autodesk Revit with the use of two-dimensional plans available in AutoCAD as shown in figure 4. The three dimensional model created with Revit was later converted to an energy model and exported as a Green Building XML (gbXML) file to Integrated Environmental Solutions (IES) software. The IES software was used for performing the energy analysis of the building. The "white box" approach was used where the various parameters' values were inputted and the simulation is run to obtain the results required(Li and Wen 2014). The above said building materials along with the glazing was created as building components in the energy simulation software since the Green Building XML (gbXML) file is not capable of transferring the properties (Nasyrov et al. 2015). Two sets of simulation were run to identify the changes observed due to the change in the building materials and glazing. The first set henceforth called as case 1 , comprises of changing the wall materials from the conventional materials and the second set henceforth called as case 2 , is by changing the glazing material as well as providing sunshade along the 4 sides of the glazing to identify the changes in indoor air temperature, internal gains, solar flux, cooling plant sensible load and the overall electricity consumption of the building. 


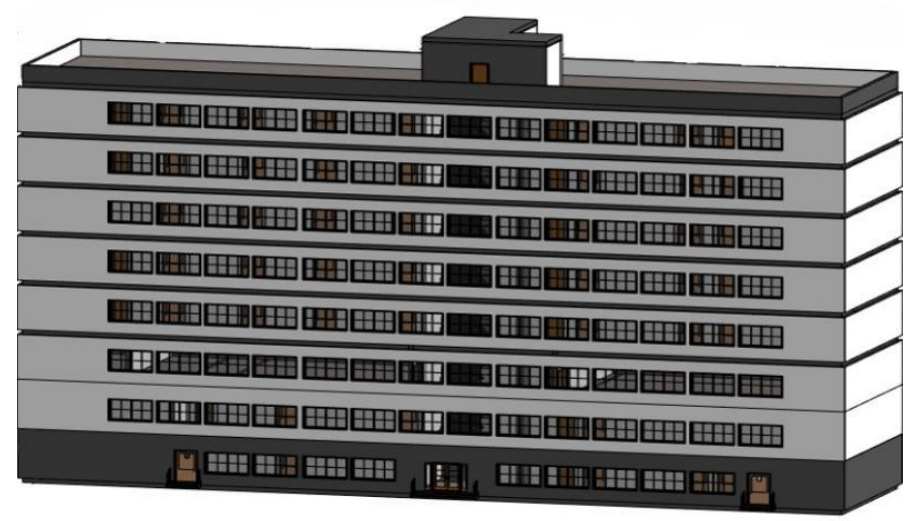

Figure: 4 Shows the building was modeled using Autodesk Revit

\section{RESULTS}

\section{External wall gains}

The conduction gain of wall materials were solely dependent on the thermal conductivity of the material where the materials with lower thermal conductivity showed lesser conduction gain while materials with greater thermal conductivity increased the total conduction gain of the walls which negatively affect the occupants of the building. More conduction of the wall results in increased thermal discomfort inside the building. The figure 5 represents the conduction gain of the rooms where the use of Autoclaved Aerated Concrete Block (AAC) showed the least conduction gain with an average of $0.75 \mathrm{~kW}$ while Compressed Stabilized Earth Block (CSEB) had an average conduction gain of $1 \mathrm{~kW}$. The concrete blocks as well as fired bricks had similar conduction gain of $1.46 \mathrm{~kW}$ due to its greater thermal conductivity. The addition of sunshades further reduced the wall gains to a negative value, which suggests that the indoor will be much cooler than the outdoor environment thus reaching thermal comfort. The comparison between the building with and without sunshade is shown in figure 5 which suggests that the application of sunshade greatly helps in cooling the indoors and can be used as a retrofitting component in the existing building. 


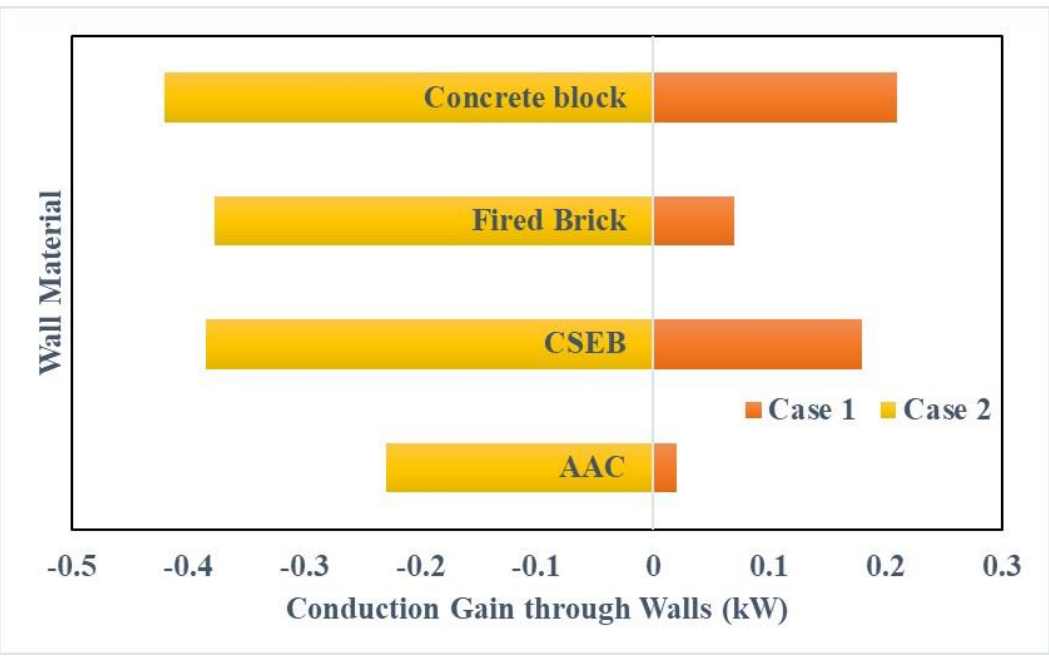

Figure: 5 Represents the conduction gain of the rooms

\section{Solar gains}

Solar gain is defined as the heat entering through the openings or the fabric of the building, which is the reason of accumulation of heat inside the building. Solar gain is one of the major factors, which determine the amount of heat build-up in the building due to the sun's heat. The conventional building and its solar gain throughout the year is represented in figure 7 . The three dimensional model of the building replaced with clear glass from the rooms to the glazing material which has better reflective and refractive properties helps in reducing the overall solar radiation entering the building along with the sunshades as shown in figure 6 . There is about $76 \%$ reduction in solar gain due to the addition of sunshades as well as the replacement of glazing material as shown in the figure 8 . The addition of sunshades greatly reduced the overall energy due to the solar radiation, which in turn can reduce the conduction gain due to that. This has a very positive effect on the thermal comfort inside the building while reducing the electricity consumption in airconditioned rooms.

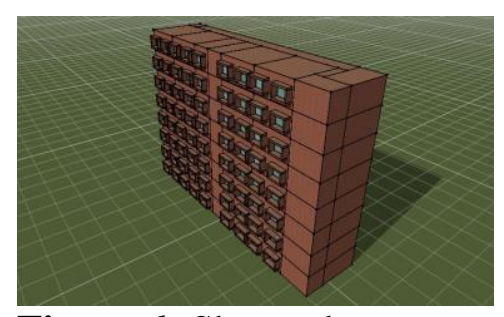

Figure 6: Shows the Building along with Sunshades.

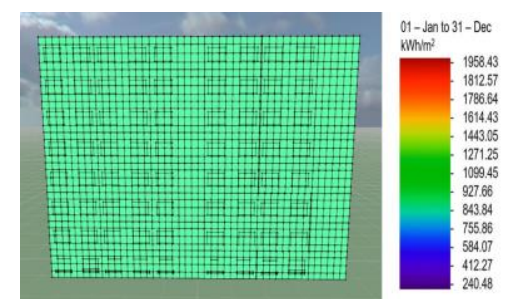

Figure 7: Shows the conventional building and solar gain.

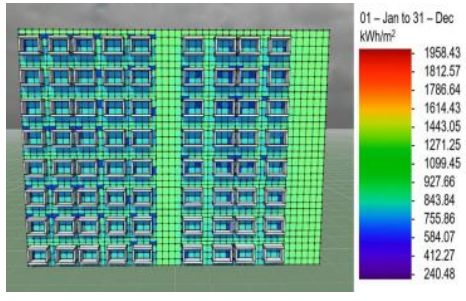

Figure 8: Shows the conventional building and its solar gain 
Figure 8: Shows the addition of sunshades as well as the replacement of glazing material

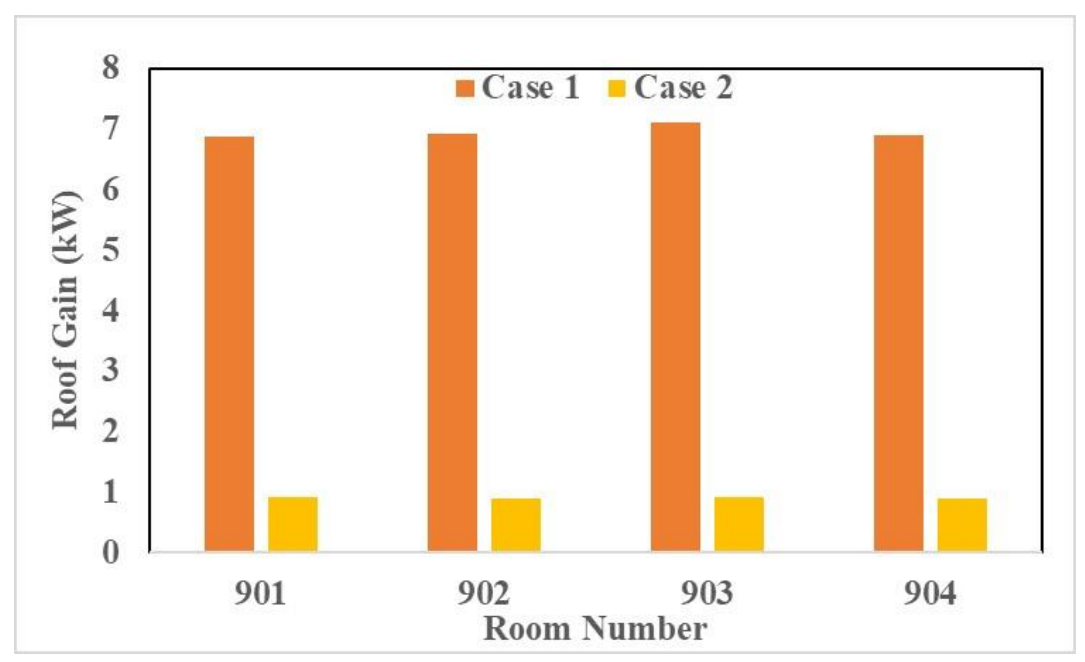

Figure 9: Shows the roof is coated with the cool roof paints

\section{Indoor Air Temperature}

The above-discussed parameters are the major contributors, which affect the indoor air temperature of the building. The conduction gains are represented in terms of energy since it is a measure of the solar radiation incident in the building envelope. The indoor air temperature is the measure of the change in the thermal comfort of the occupants with respect to the change of envelope materials. The non-air-conditioned classroom situated on the top floor of the building along the North West corner of the building was selected since it is susceptible to maximum solar radiation throughout the day for the energy analysis. The findings were represented for the hottest day of the year where the temperature rose to $48.03{ }^{\circ} \mathrm{C}$ during mid-afternoon. The figure 10 represents the indoor air temperature of the building throughout the day where the initial increase in temperature before 8 AM represents the heat build-up inside the rooms due to the windows and doors being closed during the non-occupancy hours, which is from 6 PM to 8 AM. During the hottest time of the day at around 3:30 PM the indoor air temperature stays within the range of $40{ }^{\circ} \mathrm{C}$ while fire bricks, Autoclaved Aerated Concrete Block (AAC) and Compressed Stabilized Earth Block (CSEB) are used as building material while the application of concrete blocks as the building material shows a peak of $52^{\circ} \mathrm{C}$. This can be attributed to the lower thermal conductivity of the building materials in comparison with the concrete block. The simulation data represents the feel like temperature inside the building for the occupants. The rise of indoor temperature above the external air temperature is due to the heat build-up from the solar gain, which reaches its peak value at 15:30 hours and 
reduces past that time. The rooms of the building are west facing and hence the temperature rise after noon is justified. The simulation data are also compared with the experimental values obtained for its validation.

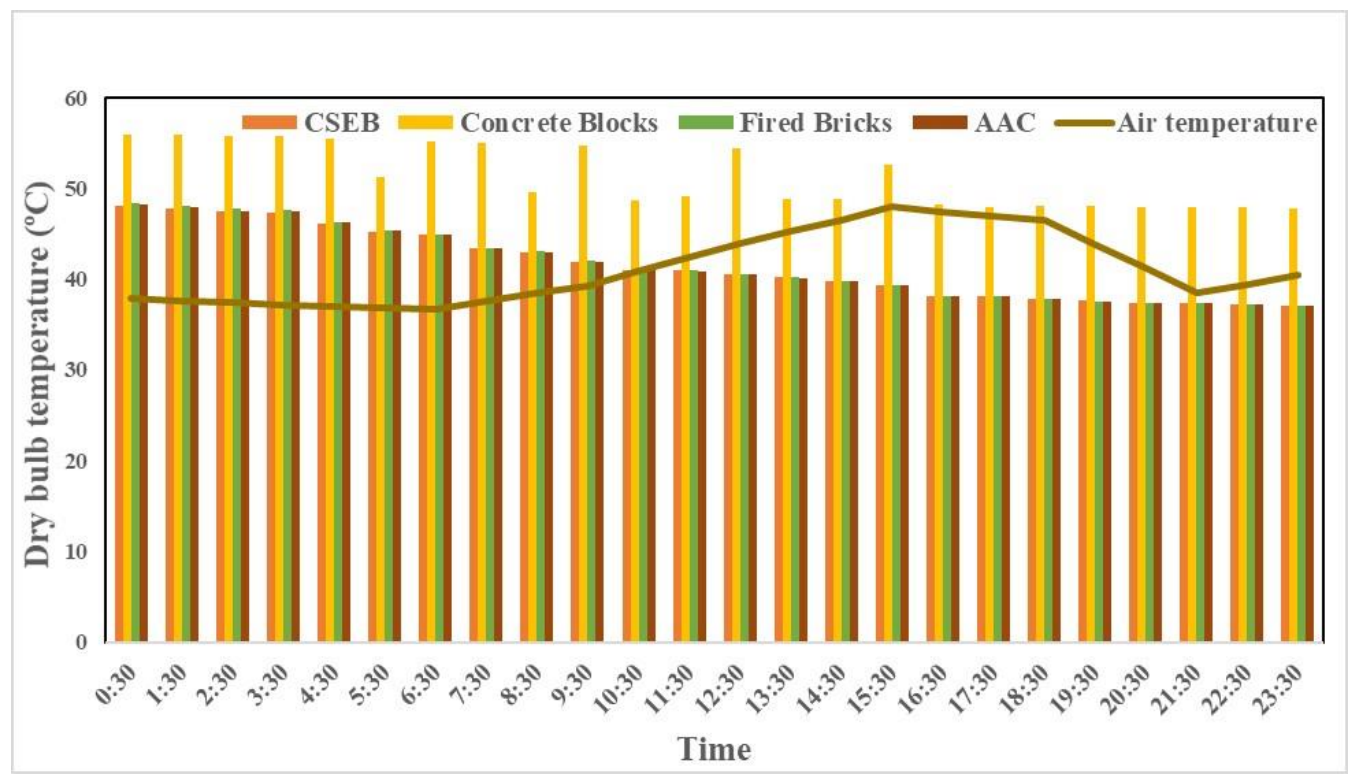

Figure 10: Represents the indoor air temperature of the building

\section{Validation of indoor air temperature}

The simulation results are to be validated to confirm the findings, which is done experimentally. Anemometer HTC AVM-06 as shown in figure 11 is used for the purpose of validation similar to the study done by Daniel Lawrence et al (Daniel Lawrence and Jayabal 2014). The anemometer helps in identifying the ambient temperature of its surrounding at any point of time along with the wind velocity, dew point temperature and wet bulb temperature. The anemometer was used to measure the indoor air temperature, which is then compared to the temperature data obtained from the simulation to understand the precision of the data obtained through the simulation. The results are tabulated in table 4, which suggests that the experimental value for both indoor and outdoor air temperature are in accordance with the simulation value. Compared to the experimental and simulation model, the temperature variance between $\pm 1{ }^{\circ} \mathrm{C}$, which proves the software's simulation data, is similar to the experimental study. 
Table 4: Comparison of experimental and analytical temperature variation

\begin{tabular}{|c|c|c|c|}
\hline \multirow{2}{*}{ Time } & \multirow{2}{*}{$\begin{array}{c}\text { External Air } \\
\text { Temperature }\left({ }^{\mathbf{}} \mathbf{C}\right)\end{array}$} & Experimental Value & Analytical Value \\
\cline { 3 - 4 } & 33.75 & 32.94 & 32.33 \\
\hline $08: 30$ & 34.13 & 33.21 & 32.79 \\
\hline $09: 30$ & 35.54 & 33.56 & 33.9 \\
\hline $10: 30$ & 35.96 & 34.45 & 35.21 \\
\hline $11: 30$ & 36.12 & 35.78 & 36.06 \\
\hline $12: 30$ & 36.38 & 36.36 & 36.21 \\
\hline $13: 30$ & 36.59 & 36.78 & 36.36 \\
\hline $14: 30$ & 36.97 & 37.08 & 36.25 \\
\hline $15: 30$ & 35.64 & 36.71 & 35.85 \\
\hline $16: 30$ & 34.82 & 35.12 & 35.05 \\
\hline $17: 30$ & & & \\
\hline
\end{tabular}

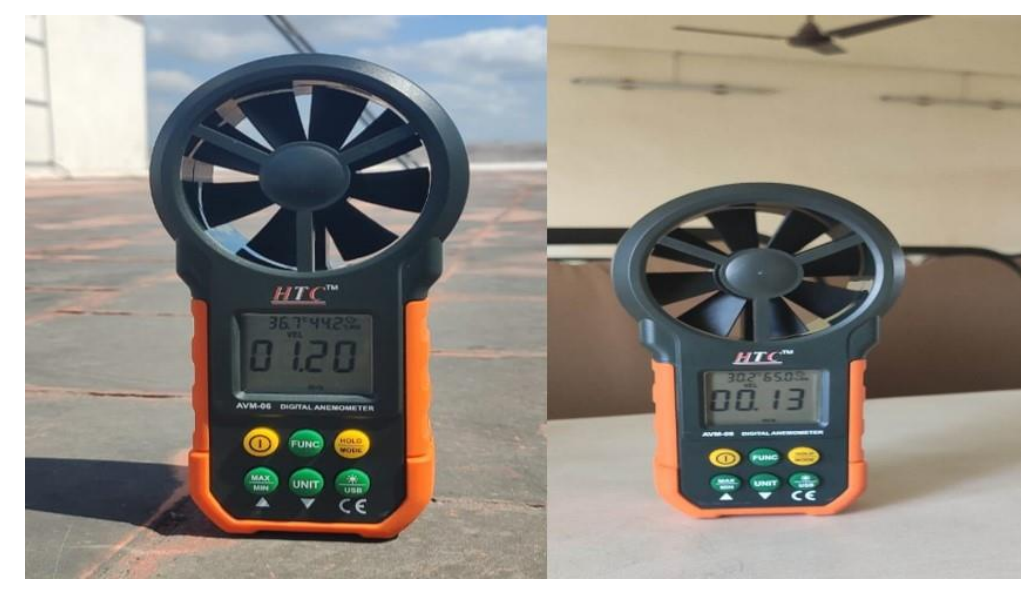

Figure: 11 Shows the Anemometer HTC AVM-06

\section{Cooling plant sensible load}

The cooling plant sensible load provides information about the required tonnage of air conditioning required for the room based on the cooling set point. This analysis helps to design the adequate amount of tonnage for the room to not increase the capital as well as operation cost of the air conditioning systems. Four rooms are air conditioned in the building with the help split air conditioners of varied tonnage of 1.5 ton and 3ton. The change of wall materials helped in reducing 
the amount of tonnage required for the rooms due to the reduction in the overall internal conduction gain. The comparison of the actual tonnage provided and the required tonnage is shown in figure 12. This suggests that the replacement of wall materials not only helps in reducing the indoor air temperature for non-air conditioned rooms but also reduces the overall tonnage required for air conditioned rooms thereby the cost incurred. The chillers load represent the total energy consumed in terms of MWh by the air conditioning system for maintaining the indoor air temperature. The chillers load was calculated for a year as shown in figure 13. It was observed that the use of Autoclaved Aerated Concrete Block (AAC) had consumed the least energy of around 130.93 MWh followed by Compressed Stabilized Earth Block (CSEB) with 136.39 MWh while fired bricks and concrete blocks consumed 147.1 MWh and 154.3 MWh respectively. This shows that there is $10 \%$ to $15 \%$ reduction in the overall energy consumed by replacement of wall materials. By further implementation of Case 2, the chillers load reduced further by $50 \%$ which suggests that the change in glazing material and the addition of sunshades has a very huge impact in air-conditioned rooms which also reduces the overall energy consumption of the building.

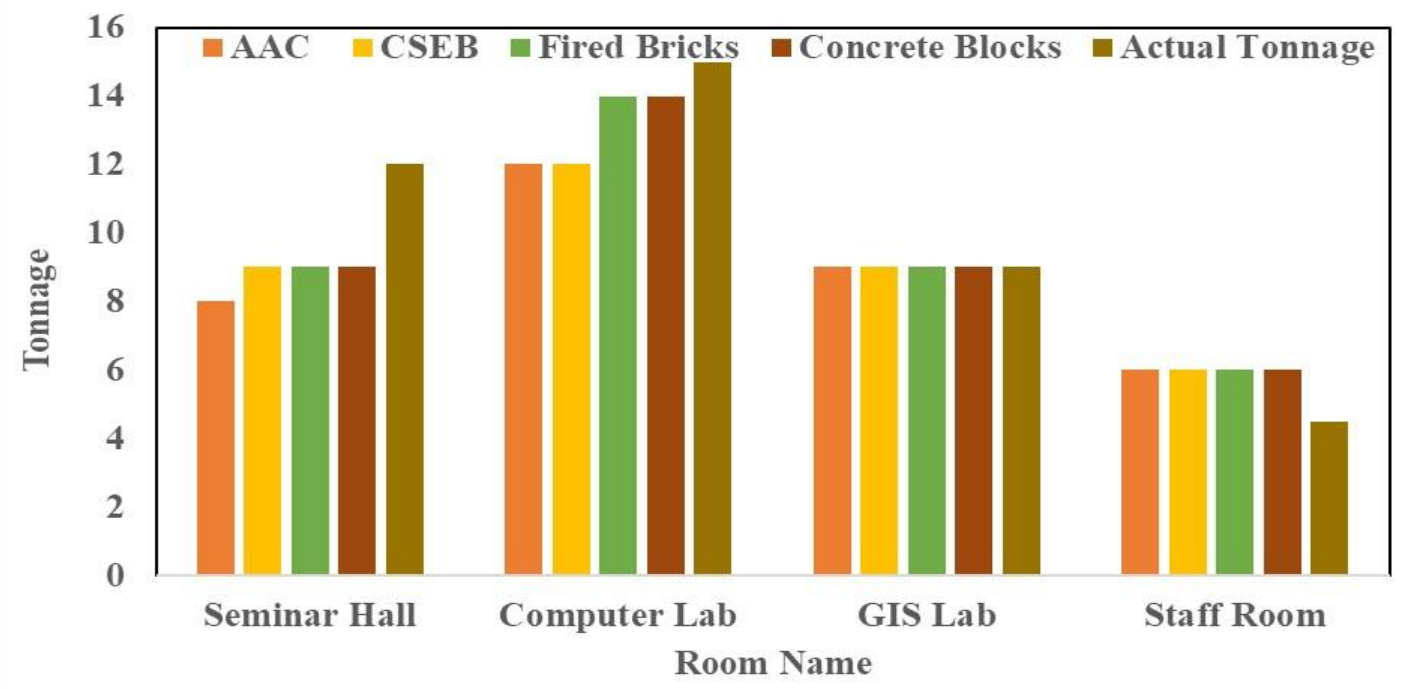


Figure 12: The comparison of the actual tonnage provided and the required tonnage

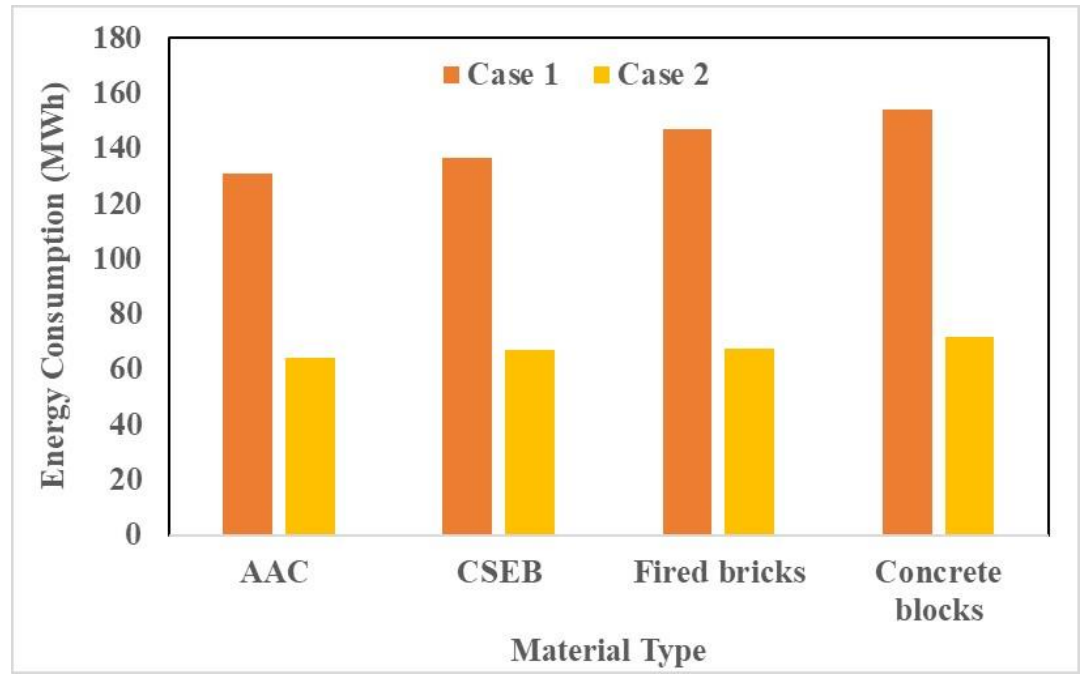

Figure 13: Shows the chillers load was calculated for a year

\section{Electricity consumption analysis}

The major requirement of performing these changes in the building wall material and glazing setup is to reduce the overall energy consumed by the building. As observed by the results above, the change of wall materials from conventional to sustainable has a positive effect on various aspects. The electricity requirement per year occupancy of the building was calculated on two cases as shown in figure 14. The first case being the typical building structure by modifying only the wall material while the second case is by change of the glazing and addition of sunshade around the window. The second case can also be considered as a retrofitting to the existing building since it is feasible to make those changes while not disturbing the structure of the existing material. The first case showed that the change of wall material has a slight significance in the reduction of the electricity consumption while the second case had a greater impact on the electricity usage with the overall reduction around $30 \%$ on comparison with the first case. 


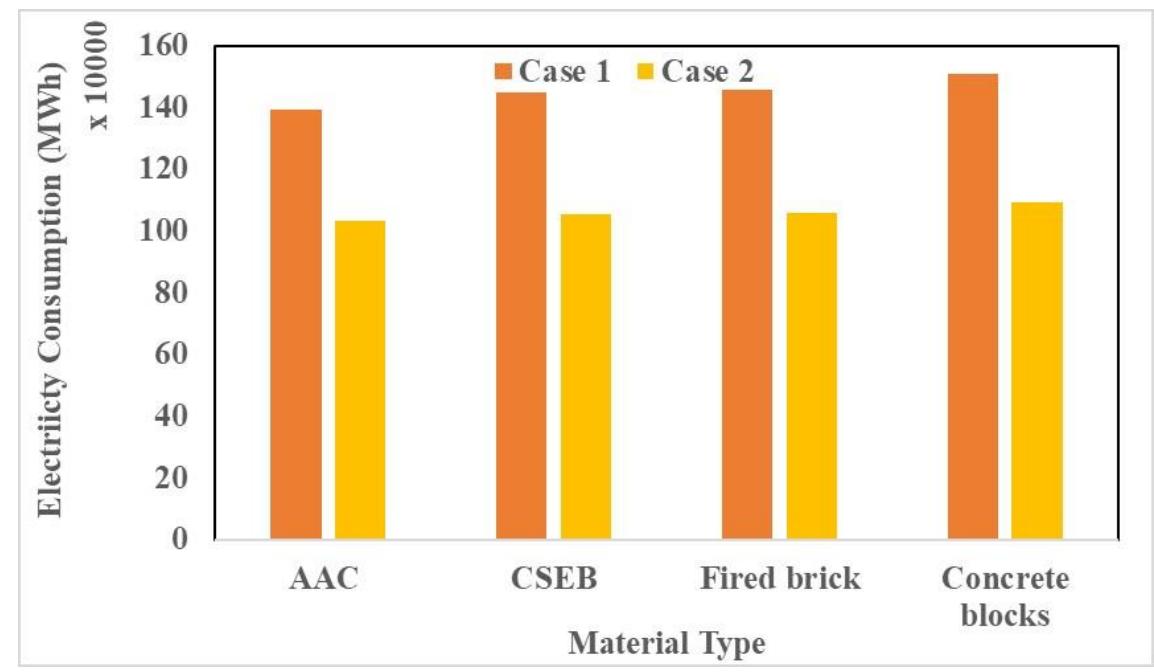

Figure 14: Shows the electricity requirement per year occupancy of the building was calculated on two cases

\section{Validation of electricity consumption}

The electricity consumption of the building was done by monitoring the daily electricity usage of the building. It was done by observing the units consumption in $\mathrm{kWh}$ during the occupancy period of the building. The monitoring was done for a period of one month to find the mean electricity usage of the building. It was observed that the minimum electricity consumption was around 250 units per day with the least occupancy and 450 units per day with complete occupancy of the building. On average around 300 units of electrical energy is being utilized by the building. On comparison with the simulation results, the consumption was around 420 units per day with the assumption of maximum occupancy. This is at par with the monitoring data observed with the help of the digital meter.

\section{CONCLUSION}

Reduction of solar gain by $76 \%$ with the change in vertical fenestration as well as addition of sunshades.

Addition of solar reflectance coating allowing only $15 \%$ of the gain in roofs on comparison with conventional roofs

Decrease in indoor air temperature by $8^{\circ} \mathrm{C}$

Reduction of chillers energy for air-conditioned rooms by $14 \%$ with the change in wall materials and by $50 \%$ with the addition of sunshades and reflective glazing.

Reduction of the overall electricity consumption of the building by $30 \%$ 
Increase in the sustainability of the building by the reduction of $15 \%$ to $48 \%$ in carbon emission and $16 \%$ to $40 \%$ reduction in the embodied carbon of the wall materials of the building.

\section{REFERENCES}

Al-Ajlan, Saleh A. 2006. "Measurements of Thermal Properties of Insulation Materials by Using Transient Plane Source Technique.” Applied Thermal Engineering 26 (17-18): 2184-91. https://doi.org/10.1016/j.applthermaleng.2006.04.006.

Ashraf, A. 2016. "Measurement of Thermal Conductivity and Diffusivity of Different Materials by the Transient Plane Source Method Using Hot Disk Thermal Constants Analyzer.” Thermal Conductivity Measurement by Hot Disk Analyzer.

Bueno, Cristiane, and Márcio Minto Fabricio. 2018. "Comparative Analysis between a Complete LCA Study and Results from a BIM-LCA Plug-In.” Automation in Construction 90 (February): 188-200. https://doi.org/10.1016/j.autcon.2018.02.028.

\section{Daniel Lawrence, I, and S Jayabal. 2014. “EXPERIMENTAL ANALYSIS AND THERMAL} COMFORT INDEX OF AIR CONDITIONED MEETING HALL.” International Journal of Research in Engineering and Technology 03 (11): 65-72. https://doi.org/10.15623/ijret.2014.0311011.

Guo, Sy Jye, and Taibing Wei. 2016. “Cost-Effective Energy Saving Measures Based on BIM Technology: Case Study at National Taiwan University.” Energy and Buildings 127: 433-41. https://doi.org/10.1016/j.enbuild.2016.06.015.

He, Yi. 2005a. "Rapid Thermal Conductivity Measurement with a Hot Disk Sensor: Part 1. Theoretical Considerations." Thermochimica Acta 436 (1-2): 122-29. https://doi.org/10.1016/j.tca.2005.06.026. - 2005b. "Rapid Thermal Conductivity Measurement with a Hot Disk Sensor: Part 2. Characterization of Thermal Greases." Thermochimica Acta 436 (1-2): 130-34. https://doi.org/10.1016/j.tca.2005.07.003.

India, Government of. 2017. Energy Conservation Building Code.

Li, Xiwang, and Jin Wen. 2014. "Review of Building Energy Modeling for Control and Operation." Renewable and Sustainable Energy Reviews 37: 517-37. https://doi.org/10.1016/j.rser.2014.05.056. 
Metz, B., O.R. Davidson, P.R. Bosch, R. Dave, and L.A. Meyer. 2008. "Climate Change 2007: Mitigation of Climate Change: Contribution of Working Group III to the Fourth Assessment Report of the Intergovernmental Panel on Climate Change." Choice Reviews Online 45 (09): 45-5006-45-5006. https://doi.org/10.5860/choice.45-5006.

Nasyrov, V., S. Stratbücker, F. Ritter, A. Borrmann, S. Hua, and M. Lindauer. 2015.

"Building Information Models as Input for Building Energy Performance Simulation - The Current State of Industrial Implementations.” EWork and EBusiness in Architecture, Engineering and Construction - Proceedings of the 10th European Conference on Product and Process Modelling, ECPPM 2014, 479-86. https://doi.org/10.1201/b17396-80.

Pezeshki, Z, A Soleimani, and A Darabi. 2019. “Application of BEM and Using BIM Database for BEM: A Review.” Journal of Building Engineering. https://doi.org/10.1016/j.jobe.2019.01.021.

Warzoha, Ronald J., and Amy S. Fleischer. 2014. "Determining the Thermal Conductivity of Liquids Using the Transient Hot Disk Method. Part II: Establishing an Accurate and Repeatable Experimental Methodology." International Journal of Heat and Mass Transfer 71: 790-807. https://doi.org/10.1016/j.ijheatmasstransfer.2013.10.062.

Monisha R, Balasubramanian M, Arul J, Kiranmayi R. 2021, A review on utilizing the marine biorefinery waste in Construction raw materials to reduce land Pollution and enhance green environment, advances in materials science, Vol. 21, No. 3 (69).

Guru Kumar, M. Balasubramanian \& Arul JeyaKumar 2021, A Review on the Mechanical Properties of Natural Fiber Reinforced Compressed Earth Blocks, JOURNAL OF NATURAL FIBERS. https://doi.org/10.1080/15440478.2021.1958405.

M S Guru Kumar., M. Balasubramanian,” Application of FGC Blocks for Sustainable Infrastructure Development 2020 IOP Conf. Ser.: Mater. Sci. Eng. 912062057.

S Dinesh Kumar Raju., M. Balasubramanian,” Experimental studies On Replacement of Steel Stirrups by Sisal Fiber Reinforced Polymers 2020 IOP Conf. Ser.: Mater. Sci. Eng. 912 